\title{
Proyección del piano valenciano en el París de entre siglos (XIX-XX): Blas María Colomer
}

\author{
Valencian Piano Projection in Paris between 19th and 20 ${ }^{\text {th }}$ Centuries: \\ Blas María Colomer
}

\author{
María Belén Sánchez García \\ Conservatorio Superior de Música de Valencia \\ belen.sanchez@csmvalencia.es
}

\section{RESUMEN}

Blas $\mathrm{M}^{\mathrm{a}}$ Colomer (1839-1917) fue el primer pianista y compositor valenciano que tuvo una importante proyección internacional al desarrollar su actividad musical en el centro cultural europeo del momento, París. Vinculado a las principales sociedades musicales e instituciones de enseñanza de la capital francesa, recibió numerosos premios, condecoraciones y distinciones como reconocimiento a su trabajo como compositor, pianista y pedagogo.

El estudio de algunos pormenores de su biografía nos permitirá ir, desde lo particular de un caso concreto, a una visión más general. Este artículo supone una aproximación al fenómeno de la música pianística y su presencia en la sociedad europea (concretamente en Francia y España, durante el periodo comprendido entre la segunda mitad del s. XIX y la primera década del s. XX) y pretende recuperar la figura de un pianista que contribuyó de manera significativa a la divulgación y pedagogía del instrumento solista más relevante del s. XIX.

Palabras clave: Blas $\mathrm{M}^{\mathrm{a}}$ Colomer, Valencia s. XIX, París ss. XIX-XX, piano valenciano, conservatorio París.

\begin{abstract}
Blas $\mathrm{M}^{\mathrm{a}}$ Colomer (1839-1917) was the first Valencian pianist and composer who had an important international projection when developing his musical activity in the European cultural center of the moment, Paris. Linked to the main musical societies and educational institutions of the French capital, he received numerous awards, decorations and distinctions in recognition of his work as a composer, pianist and pedagogue.
\end{abstract}




\section{Proyección del piano valenciano en el París de entre siglos (XIX-XX): BLAS MARÍA COLOMER}

The study of some details of his biography will allow us to go, from the particular of a concrete case, to a more general vision. This article is an approximation to the phenomenon of piano music and its presence in European society (specifically in France and Spain, during the period between the second half of the $19^{\text {th }}$ century and the first decade of the $20^{\text {th }}$ century) and seeks to recover the figure of a pianist who contributed significantly to the dissemination and pedagogy of the most relevant solo instrument of the $19^{\text {th }}$ century.

Key words: Blas $\mathrm{M}^{\mathrm{a}}$ Colomer, Valencia $19^{\text {th }}$ century, Paris $19^{\text {th }}-2^{\text {th }}$ century, Valencian piano, Paris conservatory.

Sánchez García, M. B. (2018). Proyección del piano valenciano en el París de entre siglos (XIX-XX): Blas María Colomer. Cuadernos de Investigación Musical, 4, 32-53.

doi: http://dx.doi.org/10.18239/invesmusic.v0i4.1815

\section{INTRODUCCIÓN}

En los últimos años se han revalorizado los estudios encaminados a poner de manifiesto la producción musical de personalidades que formando parte del panorama musical no parecen ocupar un papel principal o destacable. Incidiendo en este aspecto, la consulta de archivos y "recuperación" de documentos musicales ponen de manifiesto el interés por sacar del olvido repertorios histórico-musicales hasta ahora tenidos como de "segunda fila".

Los escasos pero significativos estudios musicológicos realizados hasta la fecha sobre este tema, constituyen un puzle de aproximaciones al hecho cultural, musical y pianístico y muestran el interés que despierta un periodo histórico, condicionado por los diferentes avatares políticos y específicos de cada país ${ }^{1}$. Es por ello que la personalidad de un pianista

\footnotetext{
${ }^{1}$ En este sentido, mientras en la mayor parte de los países europeos como Inglaterra, Alemania, Países Bajos o Francia, la estabilidad política y económica de sus gobiernos favoreció el auge cultural de sus respectivas sociedades, España fluctuaba entre opciones políticas dispares que provocaron su ostracismo, pese a los intentos de apertura de la periferia peninsular. El agotamiento del país durante la primera mitad del s. XIX, producido por la Guerra del Francés (1808-1814) y el enfrentamiento civil carlista (1833-1840), impidió su recuperación, lo que le hubiera permitido participar del desarrollo cultural que experimentaba Europa en esos momentos. El reinado de Isabel II (*1843-†1869) marcó significativamente a una sociedad que se regalaba a sí misma con lo castizo y cuyas inquietudes culturales no tenían por referente a Europa. No sería hasta la Primera República de 1873 el momento en que España comience su limitada apertura al exterior, basada en la producción económica de las regiones mediterráneas.

Por otro lado, la dinamización económica favoreció la aparición del pensamiento romántico y la filosofía positivista, que reflejarían una sociedad europea formada por diferentes especificidades pero convergente en el desarrollo musical. Así pues, se inicia con los estudios historicistas de finales del s. XIX un reconocimiento social, político y cultural de la música como parte fundamental en la evolución, desarrollo y formación de las sociedades europeas del momento. El panorama musical europeo de mediados del s. XIX se caracterizaba por predominio de la música germánica de carácter sinfónico, mediatizada por la influencia de la ópera italiana. A lo largo del último tercio del siglo, y en el marco del enfrentamiento bélico franco-prusiano, comienza una nueva forma de pensamiento musical en Francia. El principal foco cultural europeo del momento es la capital francesa, París. Las naciones europeas están inmersas en sus propios procesos 


\section{MARÍA BELÉN SÁNCHEZ GARCÍA}

como Blas Ma Colomer (*Valencia, 3-II-1839 - †París, 29-VI-1917) puede resultar enriquecedora a la hora de valorar y profundizar en la importancia y el papel de la música de piano dentro del panorama social y musical español y francés.

Los juicios críticos que sobre este pianista se han emitido a lo largo de tiempo han sido numerosos, siendo la procedencia de los mismos variada ${ }^{2}$. Desde la prensa musical especializada, francesa y española, en la que aparecen reseñas tanto de la actividad compositiva como interpretativa, hasta los reconocimientos institucionales que le otorgan los monarcas españoles o el gobierno francés. Así, el crítico musical francés Maurice Ordonneau (1883: 3) refiere su actividad en tres aspectos: "connu dejà comme virtuose et comme professeur, et très appréciè comme compositeur, de tout le monde artiste et élègant". Por su parte la prensa española señalará únicamente su labor compositiva e interpretativa, relegando la actividad pedagógica que desarrolló a sus años de madurez: "El Sr. Colomer con su ejecución brillante, sobre todo, en la Galop des Postillons, composición suya, se hizo aplaudir en estreno, alcanzando con justicia los elogios de los inteligentes, y obteniendo el mismo éxito en la Obertura de Guillermo Tell" (El Artista, 1867: 6).

Las referencias que nos han llegado a través de la historiografía son confusas y precisan una revisión. La primera referencia en España que tenemos sobre Blas $\mathrm{M}^{a}$ Colomer aparece en el libro "Efemérides de músicos españoles así profesores como aficionados" de Baltasar Saldoni (1860: 158) donde refiere -en la entrada "Colomer, D. Blas"- lo siguiente: "natural de Valencia; en los concursos públicos del Conservatorio de París de 1860 obtuvo, por unanimidad, el primer premio de piano, contando de edad 21 años (C)"3. Los autores valencianos Francisco Javier Blasco en "La Música en Valencia. Apuntes históricos" del año 1896 y José Ruiz de Lihory en "La Música en Valencia. Diccionario biográfico y crítico" de 1903 no recogen sino los datos que aparecen en la última publicación del musicólogo barcelonés ${ }^{4}$.

Respecto a la historiografía francesa, la obra recopilatoria "Le Conservatoire National de Musique et de Déclamation: documents historiques et administratifs" de 1900 de Pierre Constant

políticos, siendo Rusia el paradigma del prototipo de estado. La Revolución Francesa del año 1793 y las ideas ilustradas facilitaron la emergencia de una sociedad abierta y plural que sería el crisol para las nuevas concepciones y composiciones musicales; y las nuevas composiciones francesas, alejadas de las amplitudes sonoras y de la representación escénica, buscan un mayor grado de intimismo en la interpretación, en consonancia con la nueva forma de pensamiento, que coloca al hombre político y social con sus emociones en objeto de atención.

${ }^{2} \mathrm{El}$ análisis de las fuentes históricas, musicales y hemerográficas reflejan una presencia de Blas $\mathrm{M}^{\mathrm{a}}$ Colomer en la vida musical parisina importante basada en los siguientes aspectos: Las fuentes consultadas transmiten una información válida y honesta sobre los acontecimientos musicales y biográficos más relevantes. La presencia del pianista en la prensa y sociedad musical de la capital francesa es más destacable y relevante de lo que cabría esperar de un músico "llegado de fuera". La crítica sobre sus composiciones y actividades musicales es siempre en términos elogiosos, destacando sus logros como intérprete, compositor y profesor.

3 La C que aparece entre paréntesis identifica a Blas María Colomer como "compositor". En el "Diccionario biográfico-bibliográfico de efemérides de músicos españoles” (elaborado entre 1868 y 1881), el mismo autor modifica la fecha y lugar de nacimiento.

4 Consultados: el "Diccionario enciclopédico de la música" (1859) de Carlos José Melcior, el "Diccionario técnico, histórico y biográfico de la música" (1868) de José Parada Barreto y el "Diccionario de la música" (1899) de $\mathrm{M}^{a}$ Luisa Lacál de Bracho, donde no se han encontrado referencias a Blas María Colomer. 


\section{Proyección del piano valenciano en el París de entre siglos (XIX-XX): BLAS MARÍA COLOMER}

recoge entrada del pianista valenciano. Por su parte, el compositor alemán Walter Niemann ofrece la relación completa de las obras en "Klavier-Lexikon" de 1918.

Desde su época, han sido pocos los diccionarios o artículos musicográficos que se han referido a su personalidad y su obra. Los errores de documentación biográfica aparecen "enquistados" en las actuales publicaciones españolas, siendo las que más se ajustan a la realidad fáctica las francesas decimonónicas.

Además de la importancia objetiva de la elaboración de un inventario como conjunto de obras que conforman la producción musical de un compositor, conviene señalar que permite la reconstrucción de la trayectoria profesional y personal de quien pretende dar a conocer sus composiciones en el ámbito general de la cultura a la que pertenece. La recepción de este musicis corpus en España tuvo escasa visibilidad y no respondió a la difusión que tuvo en Europa ni a su envergadura y calidad intrínsecas ${ }^{5}$.

La importancia de su legado ${ }^{6}$ reside en la extensión, variedad e interés de una producción que permanece "actualizada" pese al paréntesis cronológico. No tanto por sus armonías, muy alejadas de las presentes, por cuanto su finalidad e interés interpretativo, justificado por una estética que responde a los cánones clásicos de su época y que hace trascender su música.

Es, por tanto, Blas María Colomer una de las figuras del panorama musical desconocidas hasta hoy y al que debemos rescatar del olvido. Pianista que desarrolló la práctica totalidad de su producción interpretativa, compositiva y pedagógica en París, su actividad musical traspasó las fronteras llegando a países reconocidos como exponentes culturales europeas del momento como Alemania o Inglaterra. La presentación de su perfil biográfico permitirá conocer con mayor detalle a la sociedad receptora de la misma y la profundización en el conocimiento del patrimonio cultural musical europeo.

\section{BIOGRAFÍA}

\subsection{PRIMEROS AÑOS (1840-1856)}

Blas María Nicolás Ramón Constantino Colomer Guijarro nació en la ciudad de Valencia el tres de febrero de 1839 en el seno de una familia acomodada de la que era el menor de seis hermanos. El matrimonio Colomer-Guijarro vivía con sus hijos en el barrio

\footnotetext{
${ }^{5}$ La primera obra que publicó fue la partitura para piano Marcha Triunfal: Marruecos (1860) dedicada a la reina Isabel II. Se trataba de la primera edición en folio de 14 páginas, calcografiada en París en 1860 por Moucelot: presentada por D. Casimiro Martín -en nombre del editor Mr. E. Saint Hilaire- en Madrid el 16 de Enero de 1861. La obra aparece en la p. 363 de la "Lista de las obras" presentadas en el Ministerio de Fomento en los meses de Noviembre y Diciembre de 1860 para los efectos del convenio celebrado con Francia acerca de la propiedad literaria en 15 de Noviembre de 1853 y Real Orden de 29 de Febrero de 1856.

${ }^{6} \mathrm{La}$ producción musical del pianista-compositor valenciano está formada por 274 partituras que se reparten en los diferentes géneros musicales, predominando aquellas en las que el piano aparece con función interpretativa o metodológica.
} 


\section{MARÍA BELÉN SÁNCHEZ GARCÍA}

$4^{\circ}$ del cuartel de Serranos ${ }^{7}$, manzana 197, calle Cadena $n^{\circ} 8$, en el entresuelo de una vivienda que constaba, además, de planta baja y dos habitaciones por encima del entresuelo. El edificio era propiedad de Vicente $\mathrm{M}^{a}$ Colomer, "renter" y percibía anualmente, en concepto de alquiler por dichos inmuebles, la cantidad total de 2.850 reales. La familia estaba formada por Vicente $\mathrm{M}^{\mathrm{a}}$ Colomer y Labaries, natural de Valencia (ciudad), donde recibió el sacramento del Bautismo en la Iglesia de la Santa Cruz, en el año 1796, y por Pascuala Guijarro Mocholî - dedicada a "sus labores"- también nacida en Valencia y bautizada el año 1801 en la parroquia de San Martín de la ciudad.

El matrimonio tuvo seis hijos: Vicente Colomer y Guijarro nacido en 1821, Pascual, en 1824, Cándida, en 1829, Francisca, en 1832, José, en 1837 y el benjamín de la familia, Blas María, nacido en 1839. Los seis hermanos eran naturales de Valencia y fueron bautizados en la Iglesia de la Santa Cruz.

Los primeros años de Blas María Colomer transcurrieron en uno de los barrios más populares y densamente poblados de la ciudad, que no se expansionaría hasta 1865 más allá de sus murallas. Si la nobleza valenciana residía en la calle Caballeros y calles adyacentes a ella, la clase burguesa se asentaba en el primer cuartel del Mercado y más tarde en el cuartel del Mar en busca de espacios libres y del único paseo que existía dentro de la ciudad, el de la Glorieta ${ }^{10}$.

Durante el periodo de tiempo comprendido entre 1840 y 1856, los hermanos mayores de Blas María -dedicados al "estudio" los varones de la familia y sus hermanas, "sin profesión"- abandonan el entorno familiar para formar sus propias familias. En el año 1852 muere por enfermedad el hermano de Blas María Colomer, Pascual Colomer, y la familia formada por el matrimonio y sus dos hijos menores se traslada de domicilio a la calle Huerto de Ensendra, no 7 , en el barrio $5^{\circ}$ del Cuartel de Serranos.

\footnotetext{
${ }^{7} \mathrm{El}$ mencionado cuartel contaba con escasa población burguesa y de familias nobles, acogiendo esta zona de la ciudad el porcentaje más bajo correspondiente a ambos grupos sociales.

${ }^{8}$ El término "renter" hacía referencia en la época descrita a la posesión de inmuebles en la ciudad o tierras de cultivo en municipios cercanos y que procedían de la compraventa o herencia familiar; la burguesía española, a diferencia de la del resto de Europa, no mantuvo un espíritu emprendedor, quedando relegada a la administración de las tierras de las que obtenían beneficios económicos.

${ }^{9}$ El apellido Guijarro está presente en la sociedad valenciana del momento: en 1831 Antonio Guijarro Ripoll publica en Valencia "Principios de Armonía y Modulación dispuestos en doce lecciones..."; Damián Guijarro es inspector del Real Colegio San Pablo; Francisco Guijarro, encargado de la contabilidad en la sección correspondiente del Ayuntamiento de la ciudad y Antonio Aparicio y Guijarro fue un destacado miembro del Liceo Valenciano, (sección de Literatura y Artes) que se vincularía años más tarde con el sector político conservador.

${ }^{10} \mathrm{El}$ auto acordado por la Audiencia de Valencia el 5 de octubre de 1766, conforme a la Real cédula del 13 de agosto el mismo año, dividió a la población en cuatro cuarteles: Serranos, del Mercado, del Mar y de S. Vicente. El estudio de los padrones del Cuartel de Serranos, barrios cuarto y quinto, entre 1838 y 1857 muestran una población diversa que recoge oficios diferentes como abogados, médicos, propietarios y músicos (un alto porcentaje de los cuales se ubicaba en las calles que estaban alrededor de los dos teatros de la ciudad, el Teatro Princesa y el Teatro Principal) junto a profesiones menos lucrativas como sirvientes, carpinteros o escribientes.
} 


\section{Proyección del piano valenciano en el París de entre siglos (XIX-XX): BLAS MARÍA COLOMER}

La formación musical de Blas María comenzó a la temprana edad de cuatro años de la mano de D. Pascual Pérez Gascón, organista de la Catedral metropolitana ${ }^{11}$. En estos años debió familiarizarse con los primeros rudimentos musicales -como era propio de la iniciación de los niños-, esto es, con el denominado entonces solfeo y el coro. Implícito al conocimiento del lenguaje y grafía musical era la práctica interpretativa y la compositiva. La primera se centraba, en aquella época, en el estudio del órgano, el piano y/o el violín; la segunda incluía el estudio de la armonía y la composición. Pese a que ninguna fuente explicita este punto, no cabe duda de que el instrumento con el que se inició en la práctica interpretativa fue el órgano pues además de estar vinculado a su profesor, una de sus primeras composiciones, Marcha (en Do Mayor) es para este instrumento, lo que indica un conocimiento lo suficientemente profundo del instrumento como para comenzar su producción compositiva con él.

La vinculación con la Iglesia facilitaba el contacto con la práctica del canto llano, la polifonía de atril y las composiciones orquestales. Colomer asiste a clase media hora después de los oficios de los domingos, una celebración en la que la música es ejecutada como recoge Ford (1981: 9) "[...] a base de piano y violín [...]"12.

Atendiendo a las fuentes familiares, cuatro años más tarde, en 1847, asiste como alumno a las clases de Justo Fuster, profesor de música y piano en las Escuelas Pías ${ }^{13}$ de la ciudad. Las clases que se impartían en la sala de música del citado colegio tenían una regularidad de dos veces por semana, las tardes de los jueves y domingos. Allí se reunía "Blasito Colomer" (como le recordaba afectuosamente años después su compañero Eduardo Serrano) ${ }^{14}$ con un grupo de asistentes a las clases "[...] para improvisar y

\footnotetext{
${ }^{11}$ En España, las políticas educativas del s. XIX estuvieron enfocadas fundamentalmente a la ampliación de la escolarización y la alfabetización. Así, desde principios del siglo, las capillas eclesiásticas se establecen como las principales instituciones pedagógicas musicales. Pascual Pérez Gascón (*Valencia 1802-†ibidem 1864) fue infantillo del coro de la Catedral de Valencia; alumno del maestro de capilla de la Seu levantina Joseph Pons (*Gerona, 1770-†Valencia, 1818), compuso entre otras obras, el Himno a San Vicente Ferrer con motivo del centenario de la muerte del patriarca en 1855. Compaginó su cargo de organista de la Catedral de Valencia con el de director del Real Colegio de San Pablo de Valencia.

12 Citado por Montero, M. L. (1991). "Dos visiones contrapuestas de la vida musical española del s. XIX. Los libros de viaje de Richard Ford y Hans Christian Andersen”. Revista de musicología, XIV (1-2), pp. 375-388.

${ }^{13}$ Si bien hasta la desamortización de Mendizábal -durante el Trienio Liberal (1820-1823)- el aprendizaje se realizaba de forma particular, siendo el procedimiento habitual vincularse a un instrumentista o cantante de relieve, quien transmitía la información adquirida de manos de maestros anteriores, a partir de entonces se facilita la aparición de centros pedagógicos de carácter privado. Y, a pesar de que la Constitución de 1837 nada refleja sobre materia de educación musical a lo largo de la etapa escolar, comienza a implantarse en los colegios de la ciudad levantina clases de música e instrumento fuera del horario escolar. El colegio Escuelas Pías (perteneciente a la Orden de los PP. Escolapios y que en la actualidad continúa como centro docente en la calle Carniceros de Valencia) y el de San Pablo eran las dos instituciones dedicadas a la enseñanza más reconocidas en aquel momento. A sus aulas asistían los hijos de las clases sociales medias, como propietarios, empresarios, rentistas y profesionales liberales. Así, la formación de los hijos pertenecientes a la nobleza estaba en manos de tutores privados, mientras que las de las clases más desfavorecidas dependía en última instancia de la voluntad del Ayuntamiento u organizaciones como la Beneficencia.

${ }^{14}$ Eduardo Serrano Plà (*1843-†1909), fue un miembro destacado de la sociedad valenciana de la segunda mitad del siglo XIX. El 30 de mayo de 1878 propuso a la sección de Bellas Artes (junto con otros socios de la Sociedad Económica de Amigos del País, José Ma Úbeda, Enrique Aguilar, José Ma Sales y Arturo Lliberós) la fundación de un conservatorio en la ciudad de Valencia. Con la creación del Conservatorio formó parte de la primera junta directiva como Vicepresidente de la Sociedad Económica de Amigos del País de Valencia.
} 


\section{MARÍA BELÉN SÁNCHEZ GARCÍA}

repentizar sobre las obras clásicas de los mejores maestros del piano". De los años siguientes dedicados al estudio del piano encontramos noticias del joven Colomer interpretando en el Liceo Musical de Valencia ${ }^{15}$, a la edad de diez años, programas en los que incluía, entre otras obras clásicas, Variaciones de Mozart cuya dificultad de ejecución reflejan la dedicación y alto nivel técnico del intérprete pese a su escasa edad.

En 1852 comienza los estudios de violín con D. Manuel Lloria, que a la edad de sesenta y cuatro años es el primer violín de la Capilla de Música de la Casa Real y miembro del grupo de músicos que interpretaban las óperas que una compañía italiana representaba en el Teatro Princesa de Valencia ${ }^{16}$. Los progresos que realiza son tan notables que dos años más tarde, y aconsejado por su profesor, se presenta a un concurso para la provisión de puestos de la Orquesta del Teatro Principal de la ciudad. Allí, en contacto con las obras de los grandes Maestros, cuyas partituras tenía al alcance de la mano, pudo aprender Colomer el manejo de la orquesta, su dimensión formal y sonora.

Los años siguientes los dedicará Blas María Colomer a participar en las audicionesconcierto que se celebraban en el Liceo Musical de Valencia ${ }^{17}$ y a los que asistían los socios. Las obras que formaban parte de su repertorio eran las habituales en las salas de conciertos en Europa desde principios del siglo XIX: transcripciones, reducciones y adaptaciones de arias, cavatinas, melodías y fragmentos variados de las óperas célebres del momento, adaptadas para piano, piano a cuatro manos o piano y voz; y de las obras de la literatura propiamente pianística, las variaciones de Wolfgang Amadeus Mozart Ab! vous dirai-jé, Maman fueron interpretadas por el joven pianista valenciano en el Salón del Liceo a los diez años de edad.

La música en la ciudad del Turia no quedaba relegada a los salones de la nobleza, de la incipiente burguesía o a los grandes espacios teatrales. Desde la segunda mitad del siglo XIX, eran numerosos los pequeños cafés dedicados a las tertulias en las que eran habituales la presencia de músicos solistas (piano o violín) o agrupaciones instrumentales ${ }^{18}$. En 1849, Boix (1849: 222) localiza, cercanos al domicilio de la familia Colomer-Guijarro, a la iglesia de San Nicolás y ubicados en el centro de la actividad social de la ciudad, el café Europa (en la calle del Mar), el café del teatro (frente al Teatro Principal) y el café de la Cruz (en la calle

(Vid.: Micó Terol, E. (2007). Amancio Amorós Sirvent (1854-1925) y su proyección en la vida musical valenciana (Tesis doctoral). Valencia: Universidad de Valencia.

15 El Liceo Musical fue inaugurado el 3 de febrero de 1841. Era la sede de la Academia Filarmónica que dirigía José Valero y estaba dedicada a la enseñanza musical; entre sus actividades destacaba la realización de conciertos públicos.

${ }^{16}$ En el año 1855 aparece el nombre de Lloria entre los 39 profesores que forman parte de la orquesta que acompañará Il Trovatore de G. Verdi. Biblioteca de la Universidad de Valencia, Fondos Raros, Programas del Teatro Principal y Princesa. Signatura: R-3/129, p. 215.

${ }^{17} \mathrm{La}$ asociación, que compartía el ideario del resto de las repartidas por el territorio español, en sus inicios literaria y artística, fue creada en 1836 por un grupo perteneciente a la Sociedad Económica de Amigos del País, de Valencia. En el año 1838 la reina regente $\mathrm{M}^{\mathrm{a}}$ Cristina otorga la concesión del antiguo noviciado del convento del Temple como sede social a la entidad que se conformó en Academia, cuya filosofía era formar jóvenes y ayudar en la difusión de las ideas Ilustradas y la cultura por todas las clases de la sociedad.

18 El Concordato del año 1851 entre España y la Santa Sede favoreció que muchos buenos intérpretes formados en el entorno eclesiástico y que trabajaban en él, lo abandonaran, pasándose a orquestas de teatros, cafés y bandas militares. Se crea así, un espacio social propicio a dar salida laboral a los músicos procedentes del mundo religioso. 


\section{Proyección del piano valenciano en el París de entre siglos (XIX-XX): BLAS MARÍA COLOMER}

Miguelete), que ofrecían a los clientes arreglos de las arias de las óperas de moda como parte de la consumición. Blas María ("Recherché pour tenir le piano au cafê") frecuentaba estos establecimientos en los que, además de obtener noticias de primera mano -a través de los clientes- sobre la ciudad de París y las posibilidades musicales que ofrecía ${ }^{19}$, pudo familiarizarse con la "técnica" de la improvisación y la práctica pianística de acompañar a otros instrumentos o vOz, en un repertorio de piezas breves solicitado por el público asistente; en definitiva, con la música de salón extendida por todo el continente europeo. Es en este periodo de su vida en el que podemos "localizar" su obra Lamentación 2ª Para el Jueves Santo, forma musical vocal religiosa en la que incluye el piano.

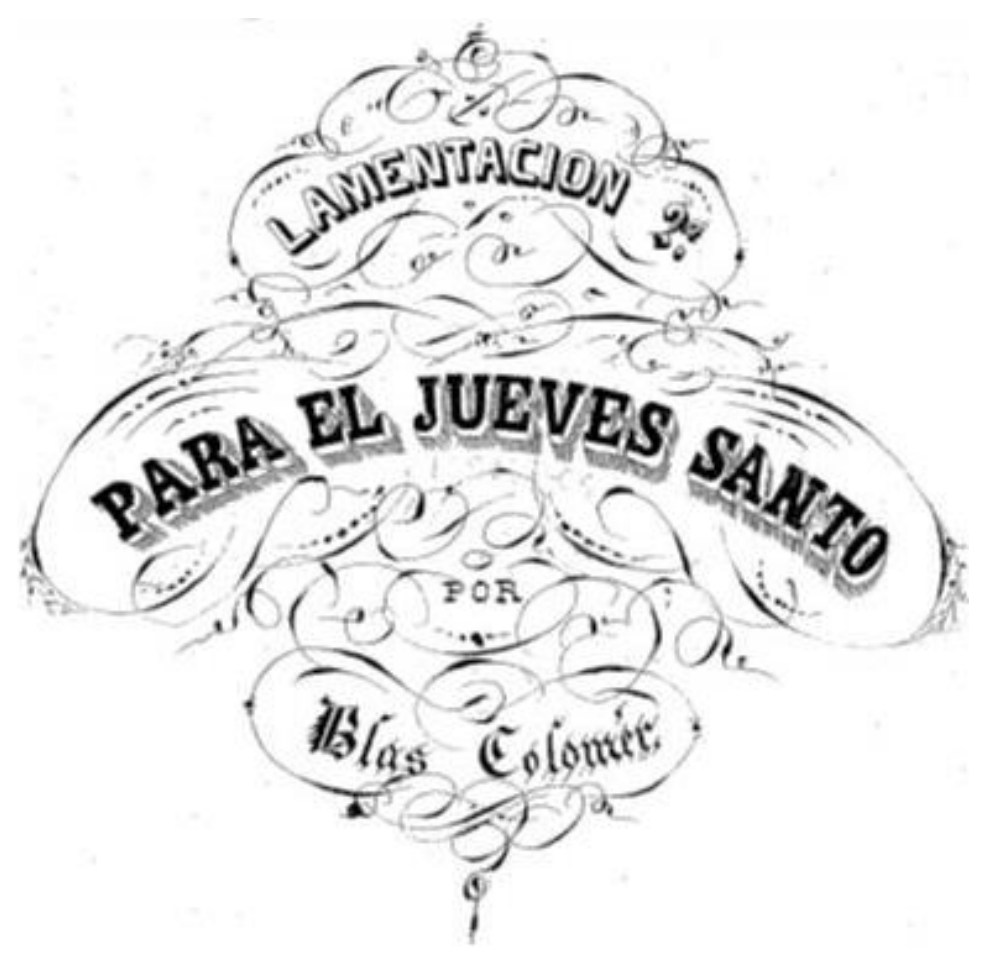

Fig. 1: Partitura para canto y piano, de Blas María Colomer

(Iglesia S. Nicolás de Valencia).

\subsection{JUVENTUD (1856-1868)}

\subsection{1.- ALUMNO DEL CONSERVATORIO NACIONAL DE MÚSICA Y DECLAMACIÓN DE PARÍS}

\footnotetext{
${ }^{19}$ No cabe duda de la atracción que la capital francesa (que compartía con Viena a principios del siglo XIX el protagonismo como centros musicales) ejercía sobre cualquier joven músico que quisiera perfeccionar su formación. Como ejemplo que nos ayude a comprender mejor el "ánimo" resulta esclarecedor el siguiente comentario de José Iturbi en la carta que dirige a Eduardo López-Chavarri Marco, el 18 de julio de 1911 desde París: "[...] no me quedaré en Valencia para dar llisonetes y cafenet. Prefiero esto último pero en París o en Alemania, en algún sitio donde se respete el arte, y en donde se tenga concepto formado de los artistas y su arte, $[\ldots]$ completamente diferente del que [...] se tiene en España y particularmente [...] en Valencia”. (Díaz y Galbis, 1996: 271).
} 


\section{MARÍA BELÉN SÁNCHEZ GARCÍA}

El veintitrés de agosto de 1856 muere la madre de Blas María Colomer, Dña. Pascuala Guijarro y Mocholí de Colomer "qu'il adorait". El fallecimiento de su madre supone para el joven pianista el final de su etapa de formación y actividad musical en Valencia. A partir de ese momento, su meta será el Conservatorio de Música y declamación de la capital francesa, a la que llegó "sans avoir aucune connaissance de la langue française, avec un modeste pécule" el 16 de septiembre de 1856, estableciendo su residencia en Avenue du Palais Royal, Galerie Valois ${ }^{20}$, T-43, como recoge su ficha de ingreso al Conservatorio de Música y Declamación.

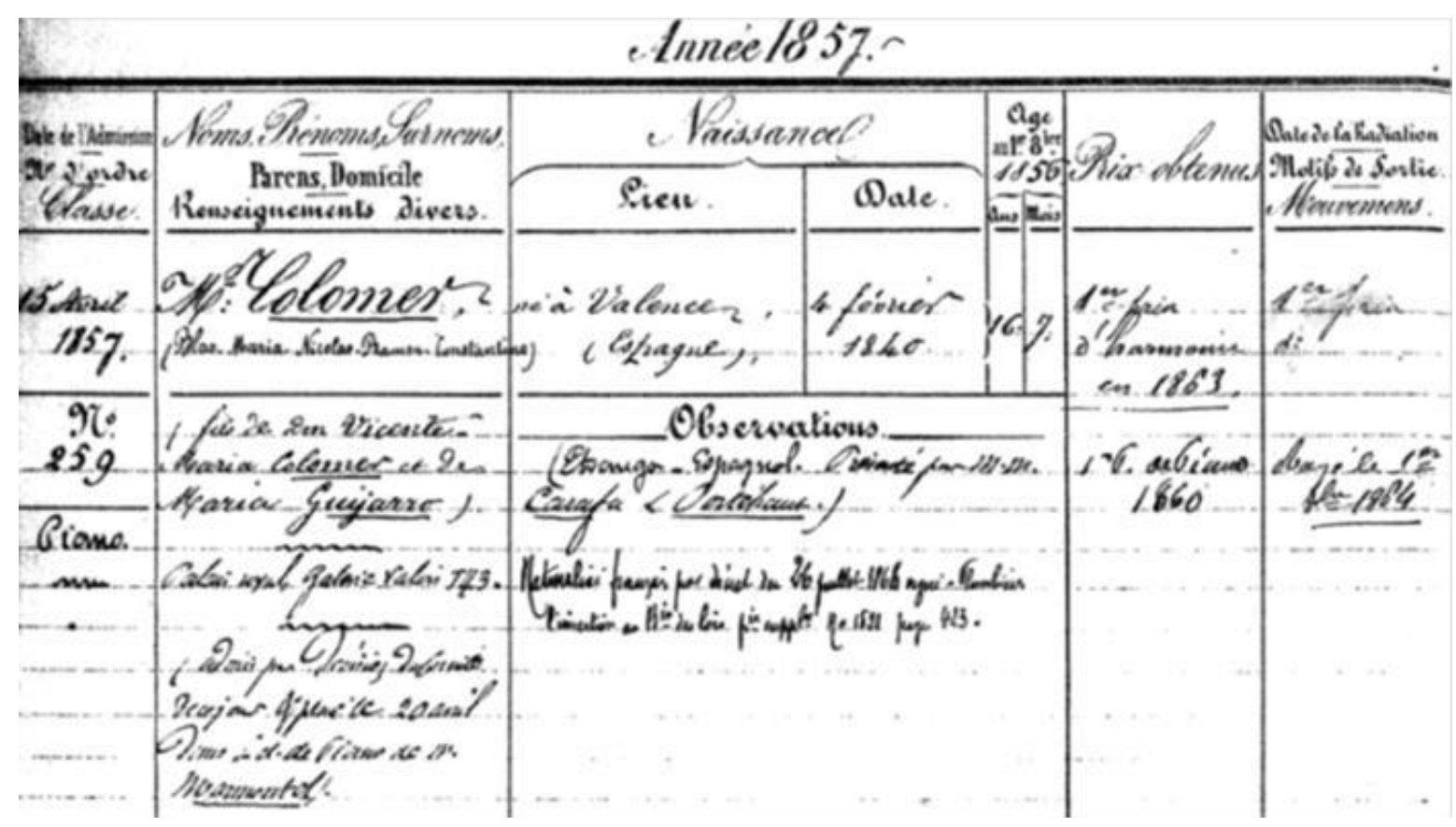

Fig. 2: Ficha de ingreso al Conservatorio de París, de Blas María Colomer

(Archives nationales France).

La cercanía al conservatorio, a la Biblioteca Real, y a los espacios de tertulia ${ }^{21}$ permitió al joven Blas participar del ambiente cultural e intelectual. La vida de los jóvenes

${ }^{20}$ Esta avenida se localizaba en el centro neurálgico social de la ciudad, en el París del recién estrenado
Segundo Imperio (1852-1870) que bajo los planos del barón Haussmann, el apoyo del emperador Napoleón
III (*1808-†1873) y el respaldo de los grupos financieros privados fomentaron las obras públicas que
renovaron y modernizaron la concepción urbanística de la ciudad. Georges-Eugène Haussmann (*1809-
†1891), prefecto de París en 1852, concibió la renovación urbanística de la ciudad medieval (con las calles
estrechas y oscuras) y la transformó en amplias avenidas con árboles (bulevares) siguiendo un plano radial. La
bonanza económica de la ciudad culminaría en las Exposiciones Universales de París de 1855 y 1867
(Exposition Universelle des produits de l'Agriculture, de l'Industrie et des Beaux-Arts) que, como en las celebradas por
los diferentes países, a nivel mundial, reflejaban la modernidad de las ciudades.
${ }^{21}$ Los lugares en los que transcurren las conversaciones que versan sobre la política española (Aymes, 2008:
73 ) son los paseos de la zona del Louvre, los teatros, los "cercles de lecture", los restaurantes y los cafés; los sitios
más concurridos se sitúan en los alrededores del Palais Royal. Por otro lado, la asistencia a los "salones", ser
admitido a ellos como participante, o intérprete de uno de los dos instrumentos con los que se identificaba la Cuadernos de Investigación Musical, 2018, junio, $\mathrm{n}^{\circ}$ 4, págs. 32-53.

ISSN: 2530-6847

DOI: $\underline{\text { http://dx.doi.org/10.18239/invesmusic.v0i4.1815 }}$ 


\section{Proyección del piano valenciano en el París de entre siglos (XIX-XX): BLAS MARÍA COLOMER}

músicos que llegaban con la expectativa de poder acceder al Conservatorio de París se repartía entre el trabajo que necesitaban para su sustento y las clases preparatorias al concurso de ingreso. Uno de los "protectores" que tuvo el joven pianista valenciano en París le facilitó la posibilidad de tomar clases con M. Portehaut y poco tiempo después fue presentado "[...] à M. Carafa, membre d L'Institut" que después de escuchar a Blas María, le presentó "[...] au grand professeur Mamontel [...]" quien le invitó a asistir a su clase en el Conservatorio como oyente ${ }^{22}$.

La recepción de Blas María en las veladas literarias y musicales de la sociedad parisina fue exitosa, ya que, a los pocos meses de llegar a la capital francesa, el 4 de febrero de 1857 "[...] tocó un concierto con mucho aplauso en el Jardín d'biver de París [...]". La obra que interpretó fue una trascripción realizada por Émile Prudent $(* 1817-\nmid 1863)$ de la Serenata de Franz Schubert.

Tras realizar el examen de admisión ante el tribunal compuesto por profesores de la especialidad el 20 de abril de 1857, Blas María Colomer fue adscrito - junto a Albert Lavignac (*1846-†1916) y Rudolph Niemann (*1838-†1898)- a la clase de piano de Monsieur Antoine-Françoise Marmontel ${ }^{23}$. El Reglamento del 22 de noviembre de 1850 del Conservatoire de Musique et Déclamation de París establece el número de alumnos por clase, ocho o más y dos oyentes, estando limitado el número de extranjeros -que, pese a gozar de los mismos derechos y deberes que los alumnos de origen francés, no podían estar en régimen de pensionado ni recibir compensación económica alguna- por curso, dado el carácter público de la enseñanza.

Blas María no es el primer español que realizará sus estudios en el Conservatorio de París. El porcentaje de músicos españoles que realizaron estudios en la prestigiosa institución europea resulta poco significativo frente a la totalidad de la matrícula de la institución a lo largo del s. XIX. Sin embargo, cabe destacar que todos ellos, en mayor o menor medida, lograron una exitosa y gratificante carrera profesional después de finalizar sus estudios.

aristocracia, el piano o el arpa, significaba "hacer su entrada en París" (Aymes, 2008: 258) y poder valerse en adelante de apoyos en la prensa, los negocios y las artes.

22 Estas clases se pagaban en metálico y eran impartidas por profesores del propio Conservatorio o concertistas reconocidos del momento. La asistencia a las mismas no constituía por sí misma una garantía de éxito en el momento de la prueba pero permitía establecer una red social intensa que repercutía directamente en la proyección artística del músico. Louis-Adolphe Portehaut (*París, 1828-†ibidem, 1880) fue profesor repetidor de la clase de Étude du Clavier (Hommes) del Conservatorio de París entre 1850 y 1863. Michel-Henri Carafa (*Nápoles, 1787-†París, 1872) fue profesor titular de composición (Hommes) del Conservatorio de París entre 1840 y 1869.

23 Antoine-François Marmontel (*Clermont-Ferrand, 1816-†París, 1898) obtuvo el primer premio de piano del Conservatorio de París el año 1832 y fue nombrado profesor titular de piano del conservatorio en 1848. En el libro del registro de alumnos de la clase de M. Marmontel del curso 1856-1857 aparecen matriculados catorce alumnos, todos varones. El censo de alumnos totales del conservatorio matriculados durante dicho periodo académico recogía una matrícula de doscientos ochenta y tres alumnos y doscientas veinticinco alumnas. La ratio por profesor en el departamento de piano oscilaba entre los diez y los catorce alumnos (externos o internos, presenciales u oyentes). 


\section{MARÍA BELÉN SÁNCHEZ GARCÍA}

En 1858, se presenta al concurso de piano que se celebra después de finalizadas las clases semestrales en la "Grand Salle de la loge d'honneur" del conservatorio, con el Allegro de Sonata, op. 58 de Chopin como obra obligada y obtiene el segundo premio ${ }^{24}$. Dos años más tarde, en 1860 y con el $6^{\circ}$ Concerto de Herz, Colomer obtendrá el Primer Premio de piano, convirtiéndose en el primer pianista valenciano y -a la luz de las investigaciones realizadas hasta la fecha y con los datos que manejamos- en el primer pianista español que obtiene tan alto reconocimiento académico de carácter internacional.

La prensa musical francesa ensalza entre elogios la interpretación de Blas María Colomer y el crítico de La France Musicale, Escudier (1860: 314), reseña:

La classe des hommes, à la tête de laquelle est placé M. Marmontel, a eu presque toutes les nominations. Sur sept lauréats, six appartiennent à cette clase [...] Son école à un cachet de distinction qui est le cachet meme de sa personne, de son esprit et de son talent. [...] Le premier prix de cette année, $M$. Colomer, est dèjá preque un artiste!! Il fera ceratinement parler de lui, comme Jules Cohen, comme Francis Planté et comme tant d'autres que M. Marmontel est justement fler de compter parmi ses élèves ${ }^{25}$.

\subsection{2.- VISITA A MADRID}

En España, la prensa pronto se hace eco del éxito del joven pianista valenciano en la capital francesa. En el periódico La Época del 2 de febrero de 1860 aparece una breve reseña informando de la inminente llegada del pianista a Madrid. Una vez en la capital será recibido por la reina Isabel II el día veinte de diciembre de ese mismo año, en una velada privada al anochecer, en la Cámara Real, a las que tan aficionada era la monarca ${ }^{26}$ y a la que asistieron distinguidas personalidades, entre las que se encontraba la duquesa de Alba. Blas María, que llevaba algunos meses en la capital española y que "no había querido tocar hasta verificarlo en presencia de nuestros reyes" 27 , interpretó el Concierto de Herz y la Marcha Triunfal Marruecos dedicada a la Reina. El éxito del pianista queda recogido en las palabras que la reina Isabel II le dedicó ante sus invitados: "es un artista que honra la Patria"28 y la

\footnotetext{
${ }^{24}$ En los concursos de piano de final de curso del conservatorio de Música y Declamación de París, en esta época, se distinguía entre premio y accésit, concediéndose tres premios y un número variable de accésits.

25 "La clase de hombres que dirige Monsieur Marmontel, ha obtenido casi todas las nominaciones. De los siete laureados, seis pertenecen a esta clase [...]. Su escuela tiene un sello de distinción que es el sello distintivo de su persona, su espíritu y su talento [...]. ¡El primer premio de este año, Sr. Colomer, ya es un artista! [La concesión del premio] hablará de él, como de Jules Cohen, de Francis Planté y de tantos otros de los que el Sr. Marmontel está orgulloso de contar entre sus alumnos” [Traducción de la autora].

${ }^{26}$ Burdiel (2004: 173) aborda la formación musical de Isabel II, de quien dice era una intérprete aficionada y sentía gran pasión por la música a pesar de la educación política que recibió de su maestro José Vicente Ventosa. Su matrimonio con Francisco de Asís María De Borbón, gran aficionado a la música alemana y cuyo profesor de piano fue Juan $\mathrm{M}^{\mathrm{a}}$ Guelbenzu (*1819-†1886), consolidó la afición del matrimonio real por las veladas musicales. En estas reuniones, en las que con frecuencia participaba la reina cantando mientras tocaba el arpa o el piano, "se escuchaban fragmentos de óperas italianas en reducción para piano, romanzas francesas, canciones andaluzas y se representaban o ponían en escena dramas castizos" (Alonso, 2004: 222).

${ }^{27}$ La Correspondencia, 22-XII-1860, p. 2.

${ }^{28}$ La Discusión, 28-XII-1860.
} 


\section{Proyección del piano valenciano en el París de entre siglos (XIX-XX): BLAS MARÍA COLOMER}

generosa recompensa que le otorga la monarca, una "riquísima botonadura de perlas y diamantes" 29 .

El concierto privado, que fue un éxito, significó "la presentación en sociedad" de Blas María y la consiguiente promoción dentro del mundo artístico musical de la capital española. La entrada a la cámara musical privada de los monarcas y, por tanto, al círculo y élite de poder del país, era la aspiración de los músicos jóvenes que, no disponiendo de más recursos que sus propios méritos académicos, aspiraban a realizar una trayectoria profesional reconocida.

Blas María está presente en el panorama musical durante el invierno de 1861 no sólo como pianista solista o pianista acompañante; también participa en conciertos que ofrecen programas de géneros variados en los que números de zarzuelas se alternan con obras más clásicas $^{30}$.

El éxito del pianista es recogido por García de la Foz en El Clamor Público (1861: 2) y ensalza sus aptitudes profesionales y celebra su disposición a participar en todos los actos "[...] con gusto $[\ldots]$ y muy satisfactoriamente $[\ldots]$ ".

\subsection{3.- DE VUELTA AL CONSERVATORIO. LAS CLASES DE ARMONÍA Y ACOMPAÑAMIENTO}

Finalizados sus estudios en la clase de M. Marmontel a la edad de veintiún años, su vinculación con el Conservatorio de París se mantiene, pues el siguiente curso (1860-1861) se matricula en la clase de Françoise Bazin para estudiar Harmonie et Accompagnement. Allí coincide con otro alumno español que un año antes, en 1860, había obtenido el tercer accésit, Espín y Pérez ${ }^{31}$. En el concurso ${ }^{32}$ celebrado el 12 de julio de 1863 se presentaron al

\footnotetext{
${ }^{29}$ El Clamor Público, 18-I-1861, p. 3.

${ }^{30} \mathrm{Al}$ igual que ocurre en París en esa época, en la capital española se celebran conciertos a beneficio de los músicos que participan en ellos o de carácter humanitario. Ante la tragedia que se produjo por las fuertes lluvias del mes de enero de 1861 en el sureste peninsular, Blas María colabora de forma desinteresada en la "función dispuesta por el señor Salas para beneficio de las víctimas de las inundaciones de Granada" (Diario oficial de avisos de Madrid, 20-I-1861, p. 4).

31 Joachim Joseph Denís Espín y Pérez (*Madrid, 1837-†1879), pertenecía a una familia de músicos e intelectuales de la corte de Madrid cuyo salón era célebre por sus veladas. Su padre, Joaquín Espín y Guillén (*1812-†1881), director de los coros del Teatro Real y organista de la Real Capilla, fundó con el musicólogo Mariano Soriano Fuertes (*1817-†1880) una de las primeras revistas musicales: La Iberia Musical y Literaria; su madre, Josefina Pérez y Colbrand (s.f.) era prima de la cantante y compositora Isabella Colbrand $(* 1785-$ †1845), primera esposa de Gioachino Rossini (*1792-†1868). El matrimonio tuvo dos hijas: Josefina y Julia Espín y Pérez (*1838-†1906), cantante de ópera y musa de Gustavo Adolfo Bécquer (*1836-†1870) que mantuvo la tradición musical de la familia.

32 El concurso que se celebraba anualmente en el Conservatorio de París dotaba de un gran prestigio al claustro de profesores y a la institución -en España, desde la creación del conservatorio en 1830 por la reina $\mathrm{M}^{\mathrm{a}}$ Cristina, las sesiones de fin de curso eran celebradas con la asistencia de la monarca alcanzando el acto un reconocimiento social y de prestigio para los participantes-. La ceremonia de entrega de los premios, presidida por altos cargos políticos en el salón del conservatorio, era el acto institucional de reconocimiento académico y social a la labor docente que la prensa de la capital francesa proyectaba a la sociedad. Las Lista des Laureats encabezaba portadas, y aparecía entre las páginas de la prensa especializada como la que presentaba La France Musical que mantenía anualmente la sección "Concours du Conservatoire".
} 


\section{MARÍA BELÉN SÁNCHEZ GARCÍA}

premio de la clase: G. Pradeau, E. Vygne, M. Rosen, Blas María y su amigo Lavignac, obteniendo éstos dos últimos un Primer Premio cada uno con la realización de un Chant Donée en La mayor y un Basse Donée en Do mayor ${ }^{33}$. En la realización del ejercicio de Basse Donée en Do Mayor, Colomer ofrecía dos propuestas diferentes como indica en la parte superior del ejercicio: "Ayant trouvé à traitier des deux manières différentes cette basse, j’ai cru bien faire de les soumettre toutes denx".

Finalizada su formación académica, en la que Blas María estableció sólidas relaciones que mantendrá a lo largo de su vida, comenzó una etapa personal que marcará su posterior trayectoria profesional: las reuniones y veladas musicales con sus compañeros de estudios franceses de quienes nos dice Soulage (1970: 215) que habían reducido su extenso nombre a "Babylas"; y las tertulias ${ }^{34}$ con artistas y músicos de la colonia española que "[...] algunas noches se reunía en el estudio de Cassadó, [...] Colomer, el gran pianista, y el pobre Arriola, [...] y Espín y Sarasate, y Padilla [...]” (Nombela, 1864: 1).

Tras esta primera etapa, valorado y respetado por el ambiente académico del conservatorio, Blas María comienza a componer y publicar obras pianísticas de variado carácter; la editora E. \& A. Girod es la primera en publicar y vender con precios de mercado sus nuevas composiciones, a las que además cataloga por su dificultad técnica: Villanelle (facile) 4 fr.; Première Mazurka de salon (difficile) 5 fr.; op. 4 Simple Chanson (-) 6 fr. El 12 de enero de 1864 contrajo matrimonio civil con "une de ses élèves", Céleste Claire Clémence Cendrier ${ }^{35}$. La familia Colomer-Cendrier celebraba el 19 de abril de 1865 el nacimiento de su primogénito, Félix Colomer, y el 19 de marzo de 1866 el de Madeleine Colomer. El compositor les dedicará las obras para piano Rêve (“à mon fils F. Colomer”) y Canzonetta (“à ma fille Madeleine Colomer").

\footnotetext{
33 ANF: AJ-37.

${ }^{34}$ Estos encuentros habituales, austeros, en los que la música presidía las veladas y los asistentes interpretaban obras del repertorio de moda o aprovechaban el encuentro para presentar sus propias obras, constituían el marco adecuado para el encuentro social y la ayuda mutua. Los espacios de reunión, en ocasiones pequeños estudios, de reducidas dimensiones, eran las viviendas habituales de los estudiantes que se desplazaban a la capital francesa, que siempre andaban escasos de recursos económicos, y albergaban lo estrictamente necesario para vivir. Con frecuencia, el estudio de piano se realizaba fuera de la vivienda, que por sus condiciones físicas y de vecindad no facilitaba la posibilidad de practicar a diario. Así, era habitual que las editoriales y tiendas de música dispusieran de una sala o espacio reservado con piano para que alumnos del conservatorio aventajados pudieran estudiar esporádicamente.

Con el tiempo, la colonia española atendería a los recién llegados y sus veladas servirían para ayudarles con una aportación mínima "cachet". A semejanza de lo que ocurría en los salones de la burguesía y nobleza española exiliada, representaban una oportunidad única para la promoción social y musical (conciertos, veladas musicales privadas y alumnos) en un entorno que ofrecía mejores posibilidades económicas. Los salones parisinos eran habituales de este tipo de reuniones, "soirées", de espíritu artístico-literario -en las que procuraban la colaboración de artistas célebres a los que invitaban a participar a cambio de suculentos refrigerios y propuestas profesionales-. Entre los más famosos estaba el de la Princesa de Polignac (cuyo esposo, el príncipe Edmond, había sido compañero de Blas María Colomer), al que años más tarde también asistiría como invitado Federico Mompou. Otros salones que destacaban en la época eran los de las cantantes líricas, aventajadas por su posición social, los cuales permitían coincidir tanto a extranjeros españoles como residentes franceses. Otros espacios dedicados a las tertulias literarias y musicales eran los talleres de los artistas, cafés y cabarets en una ciudad que era crisol de culturas.

35 La familia política de Blas María estaba plenamente integrada en la sociedad burguesa y política del momento. Alexis Cendrier (*1803-†1893) era un importante y reconocido arquitecto. La madre de su esposa, Claire Honorine Boucher, de casada Mme. Cendrier, fue empresaria y directora de su propia editorial musical.
} 


\section{Proyección del Piano valenciano EN El París de ENTRE Siglos (XIX-XX): BLAS MARÍA COLOMER}

La concesión del permiso de residencia en 1865 permite al compositor comenzar los trámites para la obtención de la nacionalidad francesa, que le será otorgada el 26 de juillet de 1868 por Décret Imperiaß ${ }^{6}$.

Durante estos años, la actividad profesional de Blas María se dirige a la composición de obras para piano solo "de salón" de claras raíces españolas -Boleras y Seguidillas, bien recibidas por una sociedad que hasta el momento no conoce sino intérpretes de música españoles pero escasa producción musical española- o de inspiración francesa como $V$ enise, Sérénade o Simple Chanson. La publicación de cada pieza (definidas por su carácter "amable" y dirigidas a un público poco exigente) va acompañada por la reseña que de las mismas hacen los principales críticos musicales de las revistas especializadas más importantes de la capital francesa, entre los que goza de gran reputación como compositor, pianista y profesor. Así, Stern (1864:4), crítico de la reconocida publicación La France Musical, de variada temática, define el estilo del pianista en las obras Villanelle, Simple Chanson y Mosä̈que Espagnol por su "parfaite élégance", "amaible simplicite", "très-élégant", de "sentiment harmonique excellent" con "[...] una coneissance parfait des ressources de l'intrument ...]".

\subsection{ESPLENDOR (1868-1900)}

Esta etapa de su vida es la más fructífera en cuanto a la producción musical y a los premios y distinciones que recibe. Blas María Colomer, que compagina la actividad profesional con la enseñanza, participa en todos los eventos sociales y académicos que favorecen la difusión de sus composiciones y el prestigio del ganador: la edición de partituras como consecuencia de la demanda académica y social que experimentó Europa a finales del s. XIX se convirtió en el paradigma de la difusión musical; las sucesivas Exposiciones Universales de París ofrecían la posibilidad de dar a conocer culturas lejanas y la promoción de la música nacional francesa; los concursos estatales de composiciones de músicos franceses promocionados por el emperador Napoleón III y las convocatorias de las sociedades musicales ${ }^{37}$ se dedicaban a dar a conocer las obras de los compositores franceses y a la promoción de los intérpretes.

\footnotetext{
${ }^{36}$ Bulletin de Lois de la Rèpublique Francaise (1869). Vol. 34, p. 423.

37 De entre todas destaca la Société Nationale de Musique, que nace motivada por el clima nacionalista tras la derrota de Sedan (1870), y el asedio de las tropas prusianas entre septiembre de 1870 y marzo 1871. Estos hechos ofrecieron la oportunidad a los músicos de París de crear una asociación de cámara diferente a las existentes en ese momento, y cuyo objetivo era la difusión de las obras de Mozart, Haydn y Beethoven. Sus fundadores, Saint-Saëns, Jules Massenet, César Franck y Henri Duparc, se posicionaban frente a la música alemana sinfónica y presentaban unas composiciones de carácter más melódico y en ocasiones intimista. La sociedad ofrecía conciertos de cámara en los que la melodía y la música para piano ocupaban un lugar importante, al lado de un número insignificante de conciertos en los que participaba la orquesta. Entre sus miembros se encontraban Alphonse Duvernoy y Alexis de Castillon. La sociedad invitó a participar en los conciertos que celebraba en diferentes salas a reconocidos intérpretes del momento como Ricardo Viñes, Pablo Sarasate, Manuel de Falla, Claude Debussy, Maurice Ravel, Alfred Cortot o Clara Haskil. Desde 1910 y hasta 1935 la sociedad pasó a denominarse Société Musicale Independante.
} 


\section{MARÍA BELÉN SÁNCHEZ GARCÍA}

Las asociaciones a las que perteneció Blas María Colomer fueron las siguientes: Société de Compositeurs de Musique; Association Départamentale; Société Nationale de Musique; Association Artistique des Concerts Populaires; Société des Concerts du Conservatoire de Paris y Société académique des Enfants d'Apollon. Entre los socios estaban los editores Léon Grus, Henri Littolff o Alphonse Leduc; los compositores Augusta Holmes, Emmanuel Chabrier, Gabriel Fauré, Vincent d'Indy o Gabriel Pierné; los intérpretes Godschalk, Benjamin Godard o el violinista Paul Viardot; los dueños de salas de conciertos Edmond Colonne, Charles Lamoreux o Pleyel-Wolff; periodistas críticos como Victorin Joncières y Oscar Comettant; el director del Conservatorio de París Theodore Dubois; organistas como Alexandre Guilmant y compañeros de estudios y amigos personales de Blas María como Émile Pessard, Francis Planté o Emile Palladilhe.

El prestigio que obtenía al recibir los premios que otorgaban las sociedades musicales le facilitaba el acceso a las principales salas de la capital francesa (Palais d'biver, Théâtred'Application, Trocadero, Cirque d'Eté, Sala Pléyel, Grand Palais Société Nationale des Beaux Arts, Château d'Eau, Concerts Lamoureux y la Salle du Conservatoire) que comenzaron a incluir en su repertorio de concierto las obras del compositor que comparten programa con otras de Johann Sebastian Bach, Georg Friedrich Händel, Fernand de la Tombelle o Cécile Chaminade.

\subsection{1.- COMPOSICIONES PREMIADAS}

En mayo de 1869, Blas María fue nombrado por el Gobierno Español "Caballero de la Orden de Carlos III" por su "virtuti et merito" como profesor y compositor de música.

En el concurso anual que celebró la Société National de Musique en 1878 (año en el que se inauguró el 1 de mayo la Exposición Universal de la Industria y Bellas Artes de París), Blas María obtuvo el premio en la modalidad de Concierto con Piano y Orquesta estrenado por Albert Lavignac al piano y Edmond Colonne como director- patrocinado por la fundación Pléyel-Wolff y por el que recibió la cantidad de 500 francos en metálico.

En 1880, la Société de Compositeurs de Musique convocó una nueva edición de premios a la composición musical presidida por el compositor y crítico musical francés Victorin Joncières (*1839-†1903). Blas María presentó su segundo Concerto pour piano et orchestre en ut minor, el Trio pour piano, violon et violoncelle y un dú para oboe y piano. El concierto, "non decernê", no obtuvo premio y tardaría tres años en ser estrenado en la Sala Pleyel. El jurado le concedió el premio, ofrecido por M. Albert Glandaz y dotado con 300 francos, por el Trio y otro premio de 200 francos por el dúo.

Punto de inflexión supuso la concesión a Blas María Colomer en 1882 de tres premios convocados en la capital francesa pues implicaron la consolidación como compositor del pianista establecido y reconocido por sus méritos en Francia. La Association Départamentel de Paris convocó un concurso de composición musical en diferentes especialidades y concedió el primer y segundo premios en la categoría de pieza sinfónica para orquesta a las composiciones Légende y Entracte polonaise, y el primer premio por unanimidad a la obra Nina en la categoría de melodía con acompañamiento de piano. La 


\section{Proyección Del PIANo Valenciano EN El París de ENTRE Siglos (XIX-XX): Blas María Colomer}

Société des Grands Concerts, le concedió el primer galardón por la Ouverture Théodoric y recibió el primer premio Diètrich por su obra para dos pianos Allegro, que interpretó con su alumna Mademoiselle Duprez en la Société d'auditions Emile Pichoz.

La Académie de Beaux-Arts, bajo la presidencia de Ambroise Thomas, le concedió el 15 de junio de 1889, el Prix Rossini por su partitura inscrita con el n ${ }^{\circ} 2$ y bajo el título Ipsius Atavus $^{38}$. Este acontecimiento fue recogido en reseñas hemerográficas de intenciones divergentes, aun cuando coincidieron en el « buen hacer » del compositor.

Consciente de la singularidad que conllevaba su participación en los concursos, en 1896 presentó, sin firmar, la ópera en seis escenas Sextus a la convocatoria a premio de la Villa de París que concedió el galardón a la composición ${ }^{39}$.

\subsection{2.- LA PRODUCCIÓN MUSICAL}

La sólida formación musical de Colomer tuvo desde el principio una base claramente acorde con las corrientes educativas españolas y francesas del momento. Si bien sus primeros años están próximos al contexto eclesiástico, Pascual Pérez Gascón introdujo en Valencia una metodología que desarrolló Guillaume Louis Bocquillon-Wilhem a principios del s. XIX en París y que estaba basada en el ejercicio de la música a nivel auditivo, vocal y gráfico. Su formación en el Conservatorio de París le hicieron conocedor de los modernos recursos de instrumentación y las nuevas combinaciones contrapuntísticas que combina en un primer momento con "las rígidas reglas armónico-compositivas habituales en la tradición eclesiástica española marcada por la influencia teórica de autores como Reicha" (Ezquerro, 1996: 153).

No cabe duda que Blas María Colomer fue un hombre de su tiempo, que vivió desde muy joven el ambiente de los teatros y los salones donde se interpretaba música civil, de baile e incluso militar. Desde su llegada a la capital francesa supo adaptarse perfectamente a las fluctuaciones de una sociedad que oscilaba entre la música clásica, germánica y tradicional y el carácter cosmopolita de una ciudad que era el crisol de los gustos y demandas de diferentes culturas. En este sentido se dedicó a la composición de formas breves pianísticas de carácter español y francés, demostrando un profundo conocimiento de las costumbres y tradiciones musicales galas. No todas tenían por destinatarios el baile o la velada en los cafés; varias, como Caprice Arabe, Hungaria o Roumaine, están pensadas para dar a conocer más allá de las fronteras naturales el carácter de los diferentes pueblos.

Su producción musical -doscientas setenta y cuatro obras en todas las variedades y extensión conocidas en aquella época- refleja un compositor prolífico, de indudable sensibilidad y con una escritura entre clásica y vituosística en la que convergían el

\footnotetext{
38 Obra para orquesta y coros basada en un poema de Mme. Judith Gauthier Les Noces de Fingal.

39 Hoy en día permanece inédita.

Cuadernos de Investigación Musical, 2018, junio, no 4, págs. 32-53.

ISSN: 2530-6847
}

DOI: http://dx.doi.org/10.18239/invesmusic.v0i4.1815 


\section{MARÍA BELÉN SÁNCHEZ GARCÍA}

clasicismo y los nuevos modelos estéticos, entre los que incluye la emergente "música española".

La recepción de las mismas se realizó a través de la crítica musical coetánea, las revistas musicales, los conciertos públicos y la venta en locales y tiendas de música. Las de mayor difusión fueron las pedagógicas para el piano, que llegaron a Inglaterra y Alemania.

Destaca, de manera porcentual, el grupo de partituras -numerosas y significativasque fueron compuestas para el piano como instrumento solista y que se pueden clasificar por su función, esto es, según a qué público se dirigen. Se trata de las englobadas con el nombre de "Música de salón", las de piano a cuatro, seis u ocho manos, las de piano de concierto (solos de concours, Menuet Fantasque o los 24 Préludes) y los métodos (el más importante, École Nouvelle, está destinado a la enseñanza progresiva, sistemática y gradual del piano; junto con el resto, resultan de gran interés pues responden a la corriente que desde el último tedio del s. XIX se despierta entre los pianistas por dejar constancia de su "manera" de enseñar) y revisiones de las Sonatas de Mozart, Kuhlau y Estudios de Cramer, en las que Blas María aporta su digitación e interpretación (expresiones dinámicas y agógicas).

\subsection{3.- LA ACTIVIDAD DOCENTE}

Blas María Colomer, a lo largo de su trayectoria profesional, puso el piano al servicio de la interpretación y la composición, en definitiva, de la creación artística. Pianista de gran talento, conocía perfectamente las limitaciones técnicas y las posibilidades del piano. Su trayectoria como concertista fue constante a lo largo de su vida, pero no como gran virtuoso del piano sino como especialista instrumental que disfrutaba con cualquier faceta musical que el piano le permitiera desarrollar, incluida la pedagógica. Esta "diversificación" profesional le permitió desenvolverse con una gran soltura en la sociedad gala, que se encontraba saturada de excelentes artistas y un mercado al servicio de los intérpretes virtuosos.

Relacionado con la élite social española y francesa, su origen español y su formación pianística francesa le otorgaron prestigio como profesor en la capital francesa. Entre sus alumnos españoles se encontraban no sólo aquellos pertenecientes a familias exiliadas por motivos políticos o que estaban establecidas en la capital por cuestiones comerciales o culturales; los alumnos que aspiraban a entrar al Conservatorio de París se preparaban en clases particulares con Blas María, cuyos contactos personales y profesionales con la prestigiosa institución académica aseguraban al candidato una buena preparación.

Entre sus alumnos, en gran número, pertenecientes a la élite social y política francesa y extranjera acreditada en París- se encontraba el pianista español jiennense Ramón María Montilla (*1871-†1921), que recibió clases en privado de Blas María (Pérez, 2008). 


\section{Proyección del piano valenciano en el París de entre siglos (XIX-XX): BLAS MARÍA COLOMER}

El entorno social y académico en el que se desenvolvía le facilitó la posibilidad de ejercer como profesor. Portador del legado que sus profesores le habían transmitido y partícipe de la corriente «moderna» pianística del momento ${ }^{40}$, en 1884 recibió del estado francés el grado de "Officier d'Académie de l'Ordre des palmes Académiques" por su dedicación docente que era ampliamente reconocida y formó parte del claustro de profesores del curso 1884-85 de "l'Académie Internationale de Musique" situada en el no 7 de la rue Royale, cuya proyección social se realizaba a través de conciertos públicos.

En 1890 Blas María trabajó en la Maison de St. Denis ${ }^{41}$ de la Légion d'Honneur como profesor (externo) de los cursos superiores de piano como muestran los epígrafes de una gran parte de sus obras de esa época, que están dedicadas a sus alumnas que pertenecían a las altas capas sociales de la burguesía francesa. En reconocimiento a su labor de pedagogo, en julio de 1891 Léon Bourgeois (*1851-†1925), ministro de Educación Nacional, concedía a Blas María Colomer el título de "Officier d'instruction Publique".

El ministro de Beaux-Arts le nombró en 1895 "Chevalier de l'Ordre National"42 con el número de orden de matrícula 52.09, por sus méritos como compositor de música, por haber sido premiado en el Conservatorio de Música de París y por ser profesor de piano de los cursos superiores la Légion d'Honneur.

Las condecoraciones oficiales y nombramientos institucionales que con motivo de su labor pedagógica recibió no harán más que incrementar su prestigio, un prestigio que traspasó las fronteras europeas cuando en abril de 1886 recibía el nombramiento de "Officier du Nissam Iftikhar" ${ }^{43}$.

\subsection{4.- MIEMBRO DE LOS TRIBUNALES DEL CONSERVATORIO DE MÚSICA Y DECLAMACIÓN DE PARÍS}

Blas María atendía en estos años, además de a sus compromisos profesionales, las clases que impartía en el Conservatorio de París en ausencia del profesor de Harmonie Emile Pessard $^{44}$. A lo largo de los años y desde que finalizó sus estudios en la clase de M.

\footnotetext{
40 En la que los intérpretes e instrumentistas del último tercio del s. XIX se lanzaron a editar colecciones metodológicas, revisiones de obras clásicas -en ocasiones facilitadas, transcritas o reducidas a cuatro manos que permitían le interpretación musical sin especiales dificultades técnicas- de ejercicios y de estudios con el fin de facilitar el acceso técnico a los instrumentos. Todo ello reflejo del papel tan importante que la enseñanza musical estaba adquiriendo en las sociedades europeas.

41 Por el decreto de 19 mayo de 1802, Napoleón I fundó una institución dedicada a la instrucción de los hijos de los militares en la que se contemplaba la práctica instrumental. Era tradición que los profesores encargados de dicha disciplina estuvieran relacionados con el Conservatorio y fueran de reconocido prestigio.

${ }^{42}$ Décret 31-octubre -1895.

43 Mención que otorgaba el Gobierno de Túnez (bajo protectorado francés desde 1881) por los servicios prestados o a personas de reconocido prestigio en el mundo artístico y cultural.

$44 \mathrm{La}$ actividad profesional como docentes y concertistas de los miembros que conformaban el claustro de profesores y la consiguiente atención a la esfera social que giraba alrededor de la misma, condicionaba las clases y el desarrollo de los programas. Esta doble vertiente, y los inconvenientes que comportaba, era percibida por los alumnos como parte de su formación, en la que combinaban el estudio de las clases con la "actividad concertística" como una muestra del futuro profesional que les esperaba al finalizar los años de estancia en el Conservatorio. Para atender a estas "eventualidades" se había instaurado, de manera no oficial,
} 


\section{MARÍA BELÉN SÁNCHEZ GARCÍA}

Marmontel, Colomer se encargó de las clases de su profesor con cierta frecuencia. El prestigio profesional de Blas María, su condición de egresado de la institución y el reconocimiento de sus compañeros no fueron suficientes, empero, para que le fuera concedida una plaza como profesor titular en el conservatorio (a pesar del incremento de los docentes que experimentó el centro en la última década del siglo XIX).

Como hemos tratado con anterioridad, era habitual que el Conservatorio de París solicitara la presencia de intérpretes de reconocido prestigio en el momento de evaluar el rendimiento y nivel de interpretación a los alumnos en el concours que se celebraba al finalizar el curso académico o en las pruebas de admisión al centro. Entre 1887 y 1902 Blas María formó parte de los tribunales para los exámenes del centro en las especialidades de piano, arpa, trompa y violín, con otros músicos como Louis Diémer, Théodore Dubois, Gabriel Pierné o Georges Pfeiffer.

Entre los músicos e intérpretes españoles que fueron convocados, en otras ediciones, a formar parte de los tribunales, estuvieron Isaac Albéniz, Joaquín Malats y Ricardo Viñes.

\subsection{MADUREZ (1900-1917)}

Con motivo de la Exposición Universal de 1900 de París, entre el 14 y el 18 de junio, se celebró el Premier Congrès International de la Musique que reclamaba el acceso de los estudios de música a la Universidad. El interés de Blas María por la consideración social de la música no se circunscribía a su participación como miembro honorario en las sociedades, y asistió como "adhérent" a las sesiones a las que se inscribieron la mayor parte de los músicos franceses. Un mes más tarde, el 18 de agosto, Le Ministère du Comerce, de L'Industrie, des Postes et des Télegraphes, le concedía la Médaille D'Argente, Grupo I, Classe 4 dedicado a la enseñanza especial artística ${ }^{45}$.

En plena madurez, Blas María tuvo el reconocimiento como virtuoso, como profesor "de tout le monde artiste et élègant" (Ordonneau, 1883: 2) y como compositor, interpretándose sus composiciones en los teatros y salas de la capital francesa en programas que incluían obras de F. Chopin, F. Mendelssohn o F. Schubert. La obra Scherzo de Blas María Colomer se interpretó en concierto en el Cirque d'Hiver, junto a una Sinfonía de Beethoven y la obra Athènes en el Chateau d'Eau.

En España, la trayectoria profesional de Blas María fue reseñada por la prensa musical, y en Valencia sus obras de piano Capricho Elegante y Aureola formaron parte del repertorio de los conciertos públicos de piano.

la costumbre de dejar a los buenos ex alumnos y de más confianza la dirección de las clases cuando los titulares debían ausentarse por motivos profesionales.

${ }^{45}$ Los pintores valencianos estuvieron desde 1860 presentes en número, importancia y producción en los principales ateliers de la capital francesa. Todos ellos recogerán las tendencias estéticas de las diferentes escuelas de fin de siglo: neoimpresionismo, simbolismo y naturalismo. En la Exposición Universal de 1900 también fue galardonado con la Medalla de Honor de la Academia de Bellas Artes, sección pintura, Joaquín Sorolla y Bastida (*1863-†1923), junto a otros diecinueve premiados. 


\section{Proyección del piano valenciano en el París de entre siglos (XIX-XX): Blas María Colomer}

Entre 1905 y el estallido de la Primera Guerra Mundial en 1914, Blas María, además de componer piezas de salón y una obra para dos pianos, elaboró un importante conjunto de obras didácticas, la mayor parte de las cuales dedicó a sus alumnas de la "Maison de Saint Denis".

El 27 de junio de 1917 murió en su domicilio, Rue Blanche nº 84, Blaise Marie Nicolas Raymond Constantin Colomer Guijarro. La noticia que aparece en el obituario, escueta, reseñaba: "compositeur [...] professeur dans les Maisons d'Education de la Légion d'Honneur".

\section{El LEgADo De Colomer}

El estudio de su formación musical, de las experiencias que como músico y compositor vivió a lo largo de su trayectoria artística, de sus éxitos y fracasos, y de su labor como docente, nos muestra un músico vocacional cuya vida estuvo dedicada al estudio y difusión de la música en todas sus dimensiones: sinfónica, operística, de cámara e instrumental, sin olvidar la música de salón.

El resultado de su trabajo pone de manifiesto dos vertientes claramente identificables en las composiciones:

En primer lugar, la estrictamente académica, seria, rigurosa y que se ajusta a los parámetros musicales del momento. Obras como los Adagios, los 24 Preludios para piano, los Solos de Concierto o su sonata para Violín y Piano (inédita) muestran el interés que el autor tenía en participar en la composición de obras de reconocido prestigio entre los más importantes compositores y músicos del momento. En este sentido, cabe destacar su labor como productor de obras técnicas o metodológicas dedicadas a la enseñanza del piano, así como de revisiones de obras pianísticas de músicos como Corelli o Mozart.

Por otro lado, destaca su faceta como creador de óperas y obras de mayores dimensiones musicales que requieren un conocimiento profundo de la composición, lo que denota una sólida formación y desenvoltura en el campo de la creación musical. Mención especial merece su producción de música de salón, cuyos antecedentes podemos descubrir en sus primeros años de formación musical en Valencia, y que ya asentado en París le permitió la solvencia económica tan necesaria para poder dedicarse a la composición de piezas de mayor reconocimiento académico.

Blas María Colomer mantuvo un vínculo emocional con su país natal que plasmó en una gran parte de sus obras. Numerosas son las composiciones, en forma de piezas breves, cuyo título, "aires" y ritmos reflejan la añoranza de una España con la que mantuvo lazos afectivos y profesionales, y el conocimiento profundo de sus raíces musicales. La influencia francesa en la obra de Blas María Colomer es el reflejo de su sensibilidad, de manera que, al igual que existen dos presentaciones y elaboraciones de su producción, existen también dos expresividades diferentes. Frente a la emocional de su tierra natal, surgen de una manera fluida y meditada las composiciones de carácter europeo. 


\section{MARÍA BELÉN SÁNCHEZ GARCÍA}

Después de su muerte, durante el periodo de tiempo comprendido entre 1917 y 1928, las composiciones de Blas María Colomer formaron parte del repertorio de la Salle del Conservatorio de París: la clase de Coro en 1921 ofreció un concierto en el que incluyó una obra sin identificar de Colomer. La clase de trompa, en 1828, utilizó Fantaisie-Légende como obra obligada de estudio. La misma obra fue obligada en los concursos de acceso a una plaza de trompa cuarta en la orquesta de la Ópera Cómica en 1921 y de la Orquesta Lamoreux.

La alumna Mlle. Marguerite se anunció en 1921 como profesora particular de piano con la indicación en el texto de haber sido "alumna de M. Colomer", y la excelente pianista Marcelle Soulage -alumna de Blas María- interpretó para radio Tour Eiffel, en noviembre de 1924, Papillons bleus et Papillons noirs. Esta misma obra se había interpretado un mes antes en Radio París sin que la reseña identificase al intérprete.

Entre 1923 y 1924 las obras de salón de Blas María Colomer fueron emitidas en adaptaciones para instrumentos solistas: Canzonetta para violín; Canzonetta para flauta: Sérénade para flauta; Chanson Rustique para piano; Chants Assyriens para flauta; Pièce en Re para flauta. Con posterioridad a estas fechas las obras de Colomer perdieron interés para los editores y a excepción de la obra para oboe no se volvieron a editar. Caso aparte es el de las obras ya impresas que siguen formando parte de los fondos editoriales hasta mediados del s. XX y la edición actual de Chants Assyriens para oboe y piano.

En la actualidad, sus composiciones se encuentran diseminadas por bibliotecas de todo el mundo, tanto nacionales, como institucionales y académicas, lo que demuestra el interés y la difusión que su obra tuvo en el pasado. El Quinttete à vent y el Solo de concours para oboe continúan siendo reeditados e interpretados en público.

Por su parte, el Catalogue General de l'Edition Musicale en France muestra los registros de la Sociedad francesa de Autores SACEM para el año de 1983: 77, 165, 207 y 233 con obras del pianista de origen valenciano.

En 2006 la colección "Patrimonio musical litúrgico valenciano", en su volumen II, presentaba la grabación de su obra para órgano Marcha.

Sin lugar a dudas, la figura de Blas María Colomer merece el reconocimiento por parte de la historiografía musical y la visibilidad de su producción musical debe hacerse presente en los programas de concierto y académicos.

\section{BIBLIOGRAFÍA}

Aymes, J. R. (2008). Españoles en París en la Época Romántica (1808-1848). Madrid: Alianza Editorial.

Boix, V. (1849). Guía de viajeros y forasteros de la ciudad de Valencia. Valencia: Imprenta de José Rius. 


\section{Proyección del piano valenciano En el París de entre Siglos (XIX-XX): \\ BLAS MARÍA COLOMER}

Bergadá, M. (1998). “Añoranza y proyección musical de España en el París de finales del siglo XIX”. Cuadernos de Música Iberoamericana, 5, pp. 109-126.

Burdiel, I. (2004). Isabel II. Madrid: Espasa Calpe.

Díaz Gómez, R. y Galbis López, V. (1996). Correspondencia de Eduardo López-Chavarri. Valencia: Consellería de Cultura, Educación y Ciencia.

El Artista, 22-VIII-1867, p. 6.

Escudier (1860). La France Musicale, p. 314.

Ezquerro Esteban, A. (1996). "El compositor Domingo Olleta (1819-1895)". Cuadernos de Música Iberoamericana, Vol. I, p. 153.

García de la Foz (1861). El Clamor Público, p. 2.

La Correspondencia, 22-XII-1860, p. 2.

La Discusión, 28-XII-1860, p. 3.

Micó Terol, E. (2007). Amancio Amorós Sirvent (1854-1925) y su proyección en la vida musical valenciana. Tesis. Barcelona: Universitat de Barcelona.

Micó Terol, E. (2014). Amancio Amorós Sirvent (1854-1925) y su proyección en la vida musical valenciana. Lleida: Institut d'Estudis Ilerdencs. Diputaciò de Lleida.

Nombela, I. (1864). “Recuerdos de París, II”. La Época, p. 1.

Ordonneau, M. (1883). Le Gaulois, p. 3.

Pérez Colodrero, C. (2008). "Ramón María Montilla Romero (1871-1921) y su aportación a la música española para piano", pp. 53-56. Simposium FIMTE: Antes de la Iberia de Isaac Albéniz.

Pérez Garzón, J. S. (coord.) (2004). Isabel II: Los espejos de la Reina. Madrid: Marcial Pons.

Saldoni i Remendo, B. (1860). Efemérides de Músicos Españoles asi profesores como aficionados. Madrid: Imprenta de La Esperanza.

Saldoni i Remendo, B. (1868-1881). Diccionario biográfico-bibliográfico de efemérides de músicos españoles. Madrid: Antonio Pérez Dubrull.

Soulage, M. (1970). “Les avatars d'un Prix Rossini en 1889”. Revue de Musicologie, 56 (2), 214222.

Fecha de recepción: 27/02/2018

Fecha de aceptación: 09/06/2018

Cuadernos de Investigación Musical, 2018, junio, $\mathrm{n}^{\circ}$ 4, págs. 32-53.

ISSN: 2530-6847

DOI: http://dx.doi.org/10.18239/invesmusic.v0i4.1815 